\title{
Retrograde dilatation via gastrostomy of a proximal esophagoileal anastomotic stricture in an infant with esophageal atresia
}

Esophageal stenosis is a common complication after surgical repair in children with esophageal atresia. The usual treatment is endoscopic dilatation. If this fails, reoperation is needed.

A male infant presented with type 1 esophageal atresia [1]. A gastrostomy was performed on day 1 after birth, definitive repair being delayed because of the long gap. Three months later an ileocecocoloplasty was performed, the ileum being anastomosed to the cervical esophagus, enabling oral feeding. At the age of 5 months, the child was admitted for malaise. Barium studies revealed a dilation of the proximal esophagus above a narrow esophagoileal anastomotic stricture (๑ Fig. 1).

Esophagoscopy using a neonatal endoscope (Pentax EG1870K, 5 mm diameter) confirmed the stricture. Repeated attempts to pass a guide wire through the stricture failed. We therefore tried to perform a retrograde dilation through the gastrostomy orifice. The endoscope was introduced from the stomach upwards to the ileocecocoloplasty, close to the stricture. A guide was pushed retrogradely through the stricture ( $\bullet$ Fig. 2) to the mouth, and dilation was performed with Savary-Wizard dilators (diameter 5 and $7 \mathrm{~mm})$.

The child is now aged 34 months and is growing with no recurrence of the stricture.

This case report shows that retrograde dilatation - requiring preexisting gastrostomy - represents an alternative when esophagoscopy fails. The assumption is that it is easier to introduce the guide wire in a retrograde manner, following the direction of progressive narrowing of the stricture. Concurrent esophagoscopy and transgastrostomy gastroscopy have already been used in adult patients with postradiotherapy eosophageal stenosis $[2,3]$. To the best of our knowledge only one pediatric experience has been reported, that of a 4-year-old boy presenting with a distal esophageal stricture follow-

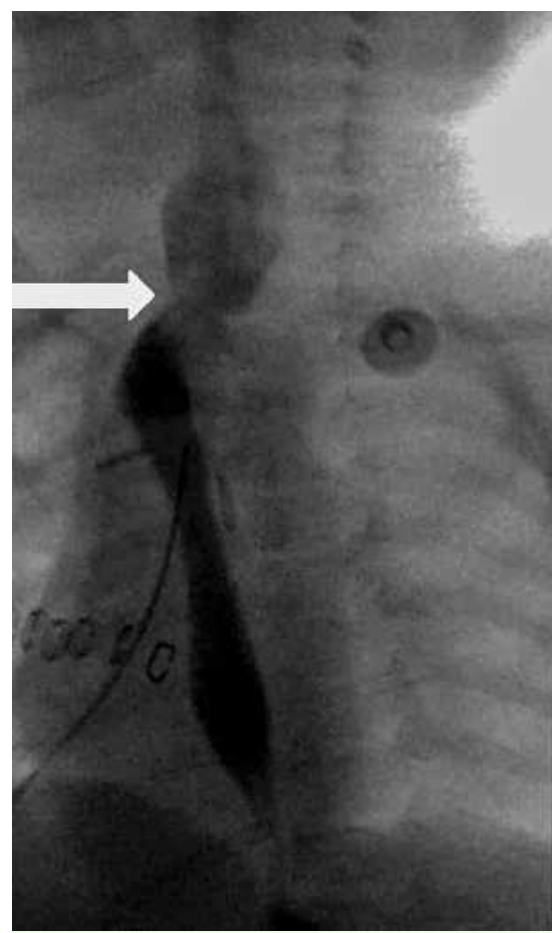

Fig. 1 Barium study showing a stricture of the ileocecocoloplasty.

ing fundoplication that was dilated in a retrograde manner via a gastrostomy orifice [4]. Our case report demonstrates that retrograde dilation through gastrostomy can be efficient in the treatment of narrow proximal esophageal strictures, even in young infants.

\section{Endoscopy_UCTN_Code_TTT_1AO_2AH}

\section{E. Macher ${ }^{1}$, L. Michaud ${ }^{1}$, D. Guimber ${ }^{1}$,} M. Bonnevalle ${ }^{2}$, D. Turck ${ }^{1}$, F. Gottrand Division of Gastroenterology, Hepatology and Nutrition, Department of Pediatrics, Lille University Faculty of Medicine and Jeanne de Flandre Children's

Hospital, Lille, France

Department of Pediatric Surgery, Lille University Faculty of Medicine and Jeanne de Flandre Children's Hospital, Lille, France

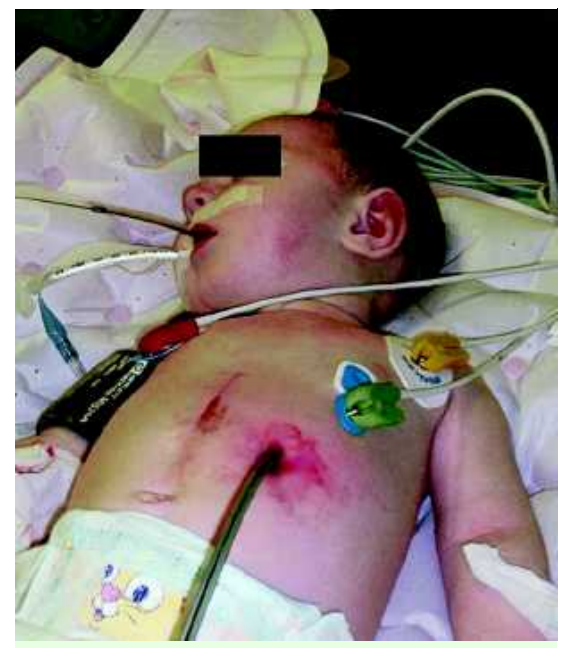

Fig. 2 The infant in the operating room, with one end of the guide and dilator entering through the orifice of the gastrostomy, the other end coming out through the mouth.

\section{References}

1 Upadhyaya VD, Gangopadhyaya AN, Gupta $D K$ et al. Prognosis of congenital tracheoesophageal fistula with esophageal atresia on the basis of gap length. Pediatr Surg Int 2007; 23: $767-771$

2 Garcia A, Flores RM, Schattner M et al. Endoscopic retrograde dilation of completely occlusive esophageal strictures. AnnThorac Surg 2006; 82: 1240-1243

3 Steele NP, Tokayer A, Smith RV et al. Retrograde endoscopic balloon dilation of chemotherapy- and radiation-induced esophageal stenosis under direct visualization. Am J Otolaryngol 2007; 28: 98-102

4 Isaiah $J H$, Jones $A B$, Lalor $E$ et al. A novel technique of a concurrent esophagoscopy and transgastrostomy gastroscopy to dilate a completely obstructed distal esophageal stricture in a child following fundoplication. Endoscopy 2005; 37: 776-778

Bibliography

DOI 10.1055/s-2008-1077649

Endoscopy 2009; 41: E10

(c) Georg Thieme Verlag KG Stuttgart · New York · ISSN 0013-726X

\section{Corresponding author}

\section{F. Gottrand}

CHRU Lille

Hôpital Jeanne de Flandre

Av. Eugène Avinée

59037 Lille CEDEX

France

Fax: +33-3-20446134

fgottrand@chru-lille.fr 